América sin Nombre, n. ${ }^{\circ} 24$ (2020): 57-68

DOI 10.14198/AMESN.2020.24-2.05

ISSN: 1577.3442 / eISSN: 1989-9831

Fecha de recepción: 30/01/2019

Fecha de aceptación: 25/03/2019
Modo de citación de este artículo:

Martínez, Alejandro. "En este país no se mueve una hoja sin que yo lo sepa”. Jardines, dictadura e intelectuales en Nocturno de Chile, de Roberto Bolaño». La nueva novela latinoamericana sin limites. Lise Segas y Félix Terrones (coordinadores). América sin Nombre, 24 (2020): 57-68, DOI: 10.14198/AMESN.2020.24-2.05

Link para este artículo: http://dx.doi.org/10.14198/AMESN.2020.24-2.05

\title{
«En este país no se mueve una hoja sin que yo lo sepa». Jardines, dictadura e intelectuales en Nocturno de Chile, de Roberto Bolaño ${ }^{1}$
}

\author{
Not a single leaf moves without my knowing.» Gardens, dictatorship and intellectuals \\ in Nocturno de Chile, by Roberto Bolaño
}

\author{
Alejandro Martínez* \\ Princeton University (Nueva Jersey)
}

\begin{abstract}
Resumen
Este artículo propone revisar cómo Roberto Bolaño utiliza la imagen y la metáfora del jardín en su novela Nocturno de Chile (2000) como expresión estética y política de la dictadura de Augusto Pinochet, de manera que se podría reflexionar en torno a la existencia de un «jardín-país» artificioso y disciplinado. En este trabajo, el jardín se comprende como expresión estética de la biopolítica, como modo de ocultar la violencia de la dictadura bajo la belleza del orden que imposibilita ver la destrucción necesaria para implantarlo. Asimismo, se analiza el rol que cumplen los intelectuales y militares representados en la novela como actores «jardineros» que establecen mecanismos de limpieza y eliminación de "malezas», es decir, de aquellos sujetos que disienten de la dictadura. El análisis permite, finalmente, dar cuenta de cómo en esta novela, así como en otras expresiones culturales chilenas, la imagen del jardín, como dispositivo de la cultura material, permite comprender las relaciones de poder en una sociedad, de sus mecanismos de ordenamiento y control, y de su afán de capturar y modificar la mirada de quienes hacen vida en ese territorio.
\end{abstract}

Palabras claves: Roberto Bolaño, jardín, dictadura, Augusto Pinochet, intelectuales

\section{Abstract}

This article reads Roberto Bolaño's use of the image and metaphor of the garden in his novel Nocturno de Chile (2000) as an aesthetic and political expression of the dictatorship of Augusto Pinochet. In his novel, I understand the garden as an aesthetic expression of biopolitics, and as a way to hide the violence of the dictatorship under the beauty of the order that makes it impossible to see the destruction necessary to implant it. Likewise, I read the representation of the intellectuals and military personnel in the novel as "gardeners» who establish mechanisms for cleaning and eliminating "weeds», that is, of those subjects who disagree with the dictatorship. The analysis gives an account of how in this novel, as well as in other Chilean cultural expressions, the image of the garden, as a device of material culture, allows us to understand the

1. Leí una versión preliminar de este artículo en el I Simposio de la Sección de Estudios del Cono Sur (LASA) 2015 bajo el título «El país como jardín en Nocturno de Chile, de Roberto Bolaño».

* Estudiante de doctorado en el programa de Español y Portugués de la Universidad de Princeton. Estudia artes visuales y literatura en América Latina, especialmente en Chile, Argentina y Venezuela. Tiene una maestría en Ética por la Universidad Alberto Hurtado (Chile), y una licenciatura en Letras por la Universidad Católica Andrés Bello (Venezuela). 
power relations in a society, of its ordering mechanisms and control, and their desire to capture and modify the gaze of those who make life in that territory.

Keywords: Roberto Bolaño, garden, dictatorship, Augusto Pinochet, intellectuals

Entre las muchas formas del jardín, hay una que destaca particularmente en la modernidad: aquella que resalta los límites, el control y el dominio sobre la naturaleza. Se trata de un tipo de jardín en el que tras una profunda limpieza se ornamenta un territorio. Este jardín captura la mirada y llama la atención sobre su materialidad, una que refleja una disposición específica, jerárquica y razonada. Para lograr este orden, el jardín necesita ser tratado cuidadosamente. Entre algunos de los rituales, el jardinero debe regar las plantas y podar los arbustos con una frecuencia específica, como lo haría un teniente rapando el cabello de los soldados de su tropa para unificarlos al imponerles el corte militar. Nada puede salirse del régimen previsto. De allí que el jardín sea también un lugar de confinamiento ${ }^{2}$, de contención, debido a que nada debe escapar de la norma ya que afea, desequilibra y pervierte el territorio. A la vez, el jardinero está en estado de alerta permanente, puesto que no puede permitir que algo no premeditado invada o se instale en ese lugar. De esta manera, el jardín puede considerarse como expresión estética de la biopolítica ${ }^{3}$. El jardín es la vida bajo un régimen normalizado y normalizador. Allí se niega la

2. Según Joan Corominas (1984), el término jardín es un diminutivo romance proveniente de la palabra jart (huerto), del francés antiguo. Esta a su vez deriva de la palabra «gard» del idioma fráncico, y significa cercado o seto. Por lo cual, pensar el país como jardín es imaginarlo como un territorio cercado, regido desde una mirada autoritaria, dictatorial. Por ejemplo, la mirada de Pinochet.

3. La biopolítica, grosso modo, puede entenderse como el conjunto de estrategias que el poder utiliza para controlar e intervenir la vida, pensando, así, el cuerpo de los individuos, o el cuerpo social, como espacio de dominio y regulación del poder. Así, la materia corporal de los individuos se torna materia de apropiación política y, como señala Michel Foucault, se pone «en entredicho su vida de ser viviente». Para una amplia revisión del concepto de biopolítica, además de los ya clásicos y fundamentales trabajos de Michel Foucault, Giorgio Agamben, y Roberto Esposito, sugiero la antología crítica Ensayos sobre biopolítica. Excesos de vida (2009), compilada por Gabriel Giorgi y Fermín Rodríguez, y Heridas abiertas. Biopolitica y representación en América Latina (2014), editado por Mabel Moraña e Ignacio Sánchez-Prado. Ambos libros cuentan con valiosas introducciones. «virtualidad» deleuzeana, ya que ningún elemento puede escapar del orden al que ha sido sometido. No hay, pues, posibilidad de la diferencia. Aquello que luce fuera de (su) lugar debe ser arrancado.

Este artículo propone analizar cómo en Nocturno de Chile (2000), de Roberto Bolaño, se utiliza la imagen y la metáfora del jardín (y de sus isotopías) como expresión estética y política de la dictadura de Augusto Pinochet. Propongo que en la novela podríamos hablar sobre un «jardín-país». En efecto, los distintos jardines representados en la novela vienen a dar cuenta de diferentes momentos de la dictadura chilena, permitiendo pensar cómo esos espacios cercados se vinculan a las esferas de poder. Asimismo, me interesa destacar el rol que allí cumplen los intelectuales, de acuerdo con Bolaño, y cómo estos se enlazan, nuevamente, con la imagen del jardín y con la figura del «jardinero». Con respecto a los jardines, hago énfasis especialmente en el estilo del jardín francés (French Formal Garden) ${ }^{4}$, que es el que más se asemeja al jardín que Bolaño representa en relación con Pinochet. Asimismo, como paradigma de jardín francés se encuentran los jardines de Versalles, y por ello durante el análisis haré mención a la figura de Luis XIV. Por último destaco la imagen del «árbol de Judas» que Bolaño utiliza hacia el final de la novela ya que se nos presenta como la "otra cara» de un jardín que no vemos, aquel en el que el artificio y la vigilancia desaparecen. Partiendo del análisis, quiero hacer énfasis en la importancia de estudiar la cultura material ${ }^{5}$ como manera de comprender las relaciones de poder en una sociedad, de sus mecanismos de ordenamiento y control, y de cómo ella puede dar cuenta de la biopolítica. La insistencia en

4. Existe una amplia bibliografía en torno a la discusión entre dos tipos de jardín contrapuestos: el jardín francés (French Formal Garden) vs el jardín inglés (English Landscape Garden). Mientras el jardín francés se vincularía a la corriente filosófica cartesiana, el jardín inglés encontraría su razón filosófica en el empirismo.

5. En parte, sigo la idea de Chandra Mukerji (1994) quien señala que "[the] material culture entered into the relations among states, when leaders used assesments of the material strengths of friends and enemies to shape their political courses» (653). 
la representación de distintos jardines (simbólica o metafóricamente) en Nocturno de Chile no es algo casual $^{6}$, sino más bien evidencia esa relación tan estrecha entre poder, cultura y violencia presente en casi toda la producción literaria de Roberto Bolaño 7. Asimismo, como señala Chandra Mukerji (1994), "the power of modern state began with intervention into nature through which a political material culture could be built» $(652)^{8}$. De esta manera, el jardín sería uno de esos artefactos que demuestran la intervención del poder del Estado moderno sobre la naturaleza, por ende, sobre la vida que se deja vivir.

\section{Los militares o sobre cómo ser jardineros}

Por este jardín-país que analizo caminan en la oscuridad los personajes Sebastián Urrutia Lacroix ${ }^{9}$ y Augusto Pinochet. La novela relata la agonía del cura Sebastián Urrutia Lacroix, quien una noche empieza a recordar distintos instantes de su vida que lo llevaron

6. La imagen del jardín es recurrente también en las novelas Los detectives salvajes y 2666. En la primera, por ejemplo, el jardín de la casa de las hermanas Font es descrito varias veces y es uno de los espacios donde ocurren acciones importantes de la historia. En 2666, donde el misterioso escritor Benno Von Archimboldi trabaja, en un tiempo de su vida, como jardinero, y una de sus novelas lleva por título «el jardín». Asimismo, el jardín como espacio aparece numerosas veces mencionado en 2666, y el narrador describe cada uno de los jardines con un número considerable de detalles.

7. Como señala Ignacio López-Vicuña (2009), «[...] en Bolaño, la literatura misma adquiere una dimensión salvaje, o más bien funciona como zona de mediación o límite entre los impulsos más refinados y la pulsión bárbara de los personajes» (200). Daniuska González (2010), por su parte, también destaca esta relación entre violencia y cultura en la obra del escritor chileno: «al mismo tiempo que vejan y ejercen la violencia, torturadores, asesinos en serie y criminales de toda índole, se dedican a la creación literaria, copiando con su letra la abyección de la sangre» (20).

8. «El poder del Estado moderno comenzó con la intervención de la naturaleza por medio de la cual la cultura material política pudo ser construida».

9. Cuando Sebastián Urrutia Lacroix, al principio de la novela, recuerda su diálogo de juventud con el crítico literario Farewell, trasunto de Alone, él le dice que no es fácil ser crítico literario. «En este país de bárbaros, dijo, ese camino no es de rosas» (14). Con ello, Farewell da cuenta justamente de que Chile no era un país ordenado bajo patrones que a él le interesan, un país difícil, un país «bárbaro». Es decir, en la metáfora que hemos planteado en este trabajo, un país sin «jardinero». a pasar de ser un joven sacerdote amante de la poesía a un cómplice intelectual de la dictadura chilena. En uno de esos recuerdos, el personaje relata cómo les da clases de marxismo a los cabecillas del régimen militar chileno tras el golpe de Estado ${ }^{10}$. Cuando Urrutia imparte su primera clase asiste uniformado con sus vestimentas de clérigo. Pareciera que, sin querer, busca mimetizarse con ese espacio uniforme en donde todos se resguardan y legitiman bajo el atuendo militar. Así como en un jardín francés ${ }^{11}$ no hay nada que pueda lucir fuera de la norma, Urrutia Lacroix ingresa a las esferas de poder asumiéndose como parte de lo que es moralmente aceptado: lo uniforme. Cuando la Junta de Gobierno entra a la sala donde se encuentra aguardando el cura, éste ve cómo «los uniformes brillaban ora como cartulinas de colores, ora como un bosque en movimiento» (108). En cierta medida, el sacerdote se enfrenta a un jardín: el jardín militar, aquel en el cual intentará "cultivar» algunos elementos de la teoría marxista, pero no para que estos «florezcan», sino, más bien, se desarrollen como anticuerpos, brindándole a los «otros jardineros» — los militares — los herbicidas necesarios para «suprimir» esas «malas hierbas» del marxismo.

A pesar de las lecciones, en este jardín de militares el cura-jardinero percibe cómo sus discípulos no terminan de comprender sus clases. La junta expulsa esa suerte de abono que les daría la "fortaleza» de enfrentarse a esa "otredad-plaga» de sus disidentes. Podríamos decir que Urrutia se convierte

10. Sus contratistas, los señores Oido y Odiem, le hacen saber que se trata de una oferta que no puede rechazar, y lo justifican diciendo que los chilenos le deben mucho a esos hombres. Ese sentido de obligación resuena a una suerte de moral kantiana que surge en las palabras de estos dos personajes. "Éste es un trabajo que nadie puede rechazar», le expresa el señor Oido. Como indica Paul Ricoeur (1990), en los preceptos de Kant hay simultáneamente tanto una exigencia de universalidad como un efecto de coerción. Lo mismo ocurre en la imagen del jardín. Ese territorio está cercado, ordenado, pensado para proyectar, como dice Foucault (1999), «la totalidad del mundo». Sin embargo, cabe preguntarse qué «mundo posible» se proyecta en este jardín de la novela.

11. El jardín francés, o French formal garden, posee unos rasgos característicos que más adelante definiremos, aunque básicamente son: la simetría, las líneas rectas y la imposición de un orden sobre la naturaleza. El jardín francés es la puesta en práctica del racionalismo cartesiano. 
en un maestro-jardinero ${ }^{12}$, aquel que instruye a sus pupilos sobre cómo diferenciar entre las "plantas» aquellas que sean «dañinas». Como refiere Zygmunt Bauman (1989), a propósito de la relación entre jardín y modernidad, «the weeds - the uninvited, unplanned, self-controlled plants - are there to underline the fragility of the imposed order; they alert the gardener to the never-ending demand for supervision and surveillance» $(51)^{13}$. Así, las «malezas» incitan la rebelión, el enfrentamiento contra el sistema establecido. Por tanto, la junta militar no puede descansar hasta no tenerlas controladas, ya que las «malezas» serían aquellos sujetos que se resisten a la imposición del jardín. Por otro lado, cabe señalar que entre sus alumnos el cura pareciera tener uno solo que le presta atención: Augusto Pinochet. El dictador, diríamos el «jardinero mayor», es el único que asiste a las clases, o no se duerme en ellas como lo haría un niño en un "jardín de infantes».

En el quinto encuentro, mientras se narra cómo el General Mendoza dormita, Pinochet lleva a Urrutia a pasear por el jardín de la casa:

De entre los macizos de flores se levantaba un aroma gustosísimo que se extendía por todo el parque. (...) Caminemos, dijo el general. Como si fuera un mago, nada más franquear el ventanal y adentrarnos en aquel jardín encantado ${ }^{14}$ se encendieron las luces del parque, unas luces diseminadas aquí y allá con un gusto exquisito $(110 \text {, cursivas mías })^{15}$.

12. En un momento de la novela en la que se relata una historia acerca de la "Colina de los Héroes», el narrador cuenta que los guardabosques del lugar "podían fungir de guardacementerios y jardineros» (57). Llama la atención esa relación estrecha entre jardín y muerte, como si el jardinero fuese aquel que se ocupa de que los muertos permanezcan en su lugar. En otra novela de Bolaño, 2666, también hay dos escenas que muestran una relación estrecha entre jardín y muerte.

13. «Las malezas - las plantas autocontroladas, no solicitadas, no planificadas - están allí para subrayar la fragilidad del orden impuesto; ellas alertan al jardinero de la exigencia interminable de supervisión y vigilancia».

14. La especificidad de «jardín encantado» le otorga un ligero sentido fantasmal y ominoso: en ese espacio hay ausencias, se percibe algo no nombrado. Por tanto, ese jardín es a la vez falta y exceso. Se sobrecarga de artificio para impedir ver aquello que se oculta: las malezas, los disidentes, lo que no puede entrar en el país/jardín del dictador/jardinero.

15. A saber, en el siglo xviI, un jardín era solo una realización posible del regente o de una aristocracia (Mukerji, 1994; Weiss, 1995). El jardín no era solo una extensión de la
Ese es el jardín que imaginaba al inicio de este texto. Uno tan vigilado que la sola presencia del dictador hace que los faros del parque se iluminen, como si cada movimiento estuviese controlado. ${ }^{16}$ Sobre esto, vale recordar la polémica frase ${ }^{17}$ que Augusto Pinochet pronunció en 1981: «no se mueve ninguna hoja en este país si no la estoy moviendo yo». ${ }^{18}$ Así, podemos imaginar a Pinochet como un jardinero que ve el país como su jardín, como ese lugar posible de ordenar a su disposición. Para Zygmunt Bauman (1998) justamente la modernidad tiene al jardín como una de sus imágenes predilectas, como una de las maneras de entender la relación entre orden y razón:

Debemos recordar que la modernidad es una época de orden artificial y de grandes planes para la sociedad, la era de los planificadores, de los visionarios y, más en general, la de los 'jardineros' que tratan a la sociedad como una parcela de tierra que debe diseñar un experto y que luego hay que cultivar y mantener de la forma prevista (147-148).

Por ello, el jardín es una imagen potente para entender el funcionamiento de la dictadura y de cómo la biopolítica es intrínseca, especial pero no exclusivamente, a ese régimen político. Por otro lado, en la novela podemos encontrar una relación entre

casa, sino una exhibición de poder, gusto, y dominio sobre la naturaleza. En ese espacio era el orden del rey lo que se representaba. De modo que el jardín es una construcción cultural, donde se exhibe una postura sobre la belleza. Es, además, territorio letrado, ya que la organización del jardín es una "escritura" de símbolos.

16. En Supervivencias de las luciérnagas, Georges DidiHuberman establece la relación entre el fascismo y los reflectores de la propaganda. En el episodio narrado por Bolańo, podemos pensar entonces cómo la presencia del dictador lo que hace es sobreiluminar un espacio para en el que, por un lado, no haya posibilidad de la resistencia en la oscuridad, y, por el otro, para que la presencia de Pinochet ocupe simbólicamente los espacios. De este modo, la metáfora de la luminosidad se acerca menos a la razón ilustrada y más a la violencia.

17. Basta hacer una sencilla búsqueda en Internet para encontrar cómo distintos artículos divulgativos y de prensa recogen esta frase entre las más controversiales de Augusto Pinochet. Sin embargo, cabe señalar que usualmente la publican modificada: «en este país no se mueve ninguna hoja sin que yo lo sepa».

18. Revista Ercilla. 13 de octubre de 1981. Consultado en http://www.lanacion.cl/las-frases-celebres-de-pinochet/ noticias/2004-12-07/144254.html 
biopolítica y la escritura del dictador. Así, el personaje de Pinochet se vanagloria de haber escrito varios libros, entre ellos uno de "geopolítica», aquella rama de conocimiento que justo busca lo que señala la cita de Bauman: tratar el territorio de la nación como una «parcela de tierra» que debe ser «diseñada». Así, pues, la geopolítica se exhibe como la «jardinería» del poder.

Por otro lado, Urrutia describe el jardín por el cual pasea con Pinochet como un «jardín encantado». Es decir, sometido a poderes mágicos, a elementos que superan la realidad, como si no fuese posible explicar el orden y aspecto artificioso, cuasi imaginario, del jardín. Por ello, en parte, me lo figuro como un jardín francés (ordenado, artificial), aquel que los arquitectos ingleses de hace tres siglos rechazaron abogando por uno más «natural», más «libre» (cf. Fariello, 2004). De acuerdo con Allen Weiss (1995), el French Formal Garden (jardín formal francés) se caracteriza por mostrar una «naturaleza forzada». Es decir, podría decirse que en el jardín francés coinciden simultáneamente tanto una falta (lo que se ha eliminado, borrado, desaparecido) como algo impuesto por una fuerza externa (la mano del jardinero que decide qué cortar). El jardín francés exhibe entonces la violencia que ejerce la biopolítica para controlar la vida. Por otra parte, Chandra Mukerji (1994) encuentra que los jardines de Versalles, cumbre del estilo francés, representan claramente el poder absolutista del reinado de Luis $\mathrm{XIV}^{19}$, a la vez que evidencian las técnicas que se han desarrollado en Occidente para controlar y dominar la naturaleza ${ }^{20}$.

\section{El jardín como máscara de la dictadura}

Los jardines de Versalles, al igual que otros del siglo XVII que siguen el estilo "formal», no deben

19. "Versailles was a model of material domination of nature that was presented as a token of the strenght of France» (Mukerji 652).

20. "Though examining how the French government in the late seventeenth century transformed the French landscape and provided technical means for doing so, we can learn more about how the Western heritage of state politics from that time has been embedded in the relations to 'nature' that we in the West work from (and against) today (...) The power of modern state began with intervention into nature through which a political material culture could be built» (Mukerji 651-652). comprenderse como una pura expresión estética, sino también como una manifestación política del absolutismo ${ }^{21}$. Asimismo, no pasa desapercibido que la esquematización, la simetría, y la profusión de las líneas rectas dan la idea de un vínculo con el mundo militar, como si el orden solo fuese posible bajo un «disciplinamiento de las formas». Incluso, Luis XIV quiso ir más allá en el control de sus jardines. El «Rey Sol» estuvo involucrado en la construcción y ampliación de los jardines de Versalles, incluso priorizándolos por encima del propio palacio ${ }^{22}$. Tal fue su participación, y su deseo por imponer el orden en su reinado, que escribió las instrucciones sobre cómo debía pasearse en los (sus) jardines, como bien explica Allen Weiss:

Louis XIV was doubtlessly aware of the profoundly formless aspect of his formal gardens, which led him to write Manière de monstrer les Jardins de Versailles (The Manner of Viewing the Gardens of Versailles), a guide indicating the itinéraire du Roi (the king's intinerary), which he imposed upon the visitors to his gardens $(47)^{23}$.

No podemos dejar de vincular esta idea, salvando el contexto, con la famosa frase ya mencionada de Pinochet. Mientras Luis XIV impuso una manera de pasear por sus jardines (lo que vendría a ser una manera de estar en su reino), y Augusto Pinochet declaró que nada podía moverse en su país (usando la imagen de las hojas) sin que él lo supiera. Ambos establecen un orden que debe ser seguido. Un orden que, hasta cierto punto, se logra "domesticando» la vida. Por tanto, no importa quiénes habiten en su territorio, tan solo vale que sigan patrones establecidos. La vida, entonces, se reduce a encajar en una forma determinada de sociedad, una que establece el «jardinero».

A propósito, la mención que hacemos a Luis XIV no es tampoco casual, sino justo tiene que ver con

21. «The royal gardens in seventeenth-century France with their miniaturized but dramatic displays of land control, which were routinely used for impressing foreign visitors, played with technique to convey power over place» (Mukerji 653).

22. «Louis XIV began building the great gardens at Versailles before he began expanding the chateau there» (Mukerji 659)

23. "Luis XIV estuvo, sin duda, consciente del aspecto profundamente informe de sus jardines; lo que lo llevó a escribir "Manera de ver los Jardines de Versalles", una guía indicando el itinerario del Rey, que él impuso a los visitantes de sus jardines». 

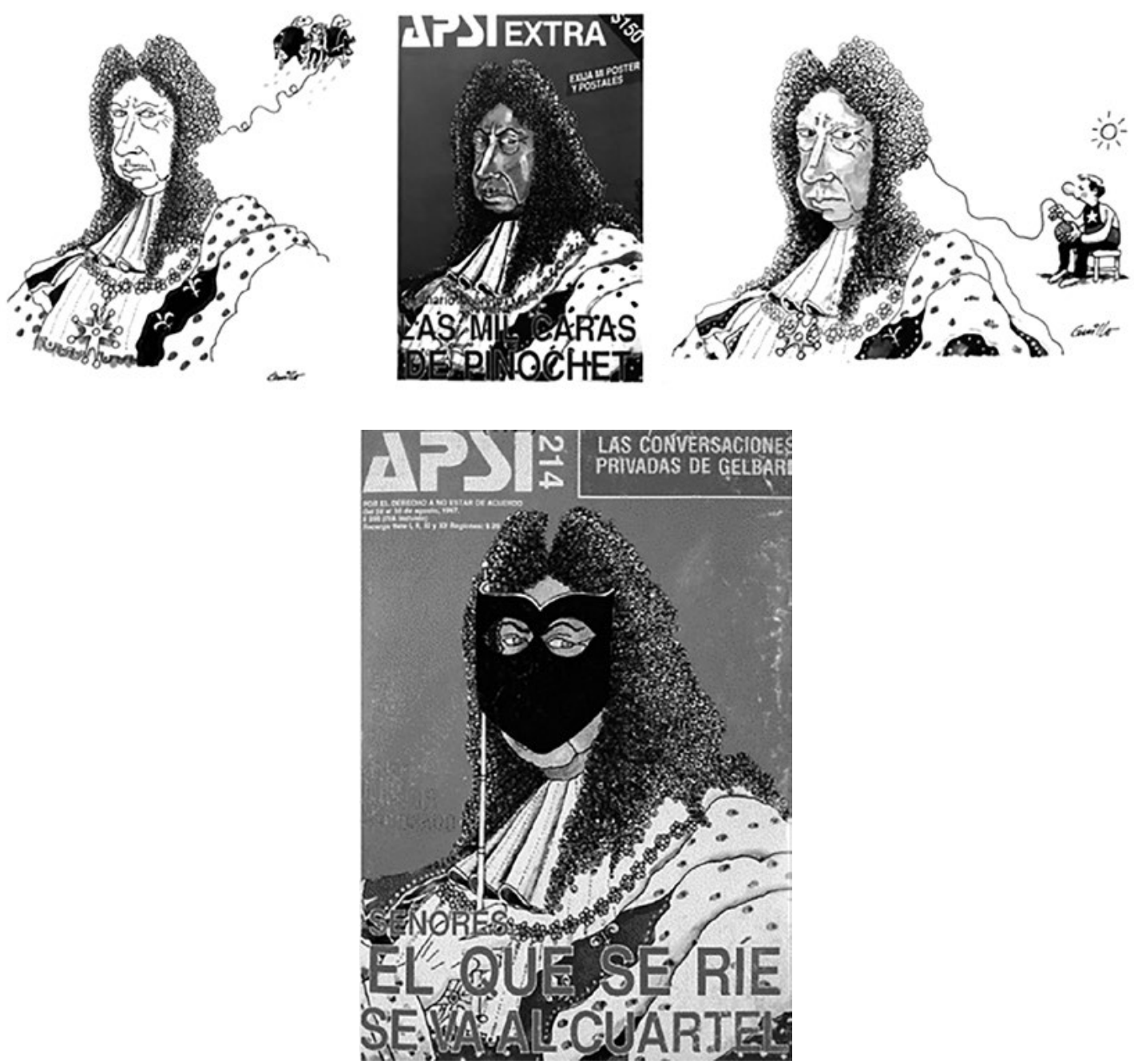

(Revista APSI. $N^{\circ} 214$. Agosto, 1987)

cómo se percibía a Augusto Pinochet. En agosto de 1987 el humorista chileno Guillo dibujó una caricatura de Pinochet emulando a Luis XIV, la cual iba a servir como portada de un número especial de la revista $A P S I^{4}$. Sin embargo, ese número no llegó a circular. "Los militares llegaron a la imprenta y se llevaron todos los números» (Araya 34). Esa caricatura causó malestar en el dictador, quien mandó encarcelar al director de la revista (cf. Araya). Posteriormente, se realizó otro número en el que la portada se autocensura paródicamente al colocarle un antifaz a la caricatura.

24. APSI (Agencia de Prensa de Servicios Internacionales) fue una revista de oposición durante la dictadura de Pinochet. Publicó 511 números entre 1976 y 1995.
Llama la atención el estilo «florido» tanto del cabello como de la ropa de la caricatura. Da la sensación de ver un jardín, no solo por las flores que adornan la túnica del personaje, sino también, en el caso de la portada autocensurada, porque el antifaz brinda ese sentido de ocultamiento propio del jardín, como hemos mencionado. Además, la idea del atuendo, de "uniformar» la caricatura de Pinochet con un ropaje semejante al de un monarca, brinda también la posibilidad de pensar que hay algo retrógrado en la forma de actuar de ese personaje, como si aparentase un rol fuera de su tiempo; como si su forma de legitimarse fuese solo a través del uniforme, del artificio, de la retórica. Por otro lado, el antifaz cubre el rostro, pero no la mirada. Los ojos de Pinochet observan, vigilan, sin alterar aparentemente al personaje ya que se hace imposible ver sus gestos faciales debido a la máscara que lleva. Así 
funciona el jardín de Pinochet. Cuando en la novela de Bolaño, el personaje de Urrutia Lacroix llega por primera vez a la casa donde se encuentra Pinochet, cuenta: «seguí a Pérez Larouche. Este se dio cuenta de que miraba buscando a los soldados de guardia y me explicó que una buena guardia es aquella que no se ve. ¿Pero hay guardia?, dije. Por supuesto, y todos con el dedo en el gatillo. Me alegra saberlo, dije» (107). La guardia, los gestos del vigilante, están escondidos tras la máscara, tras la ornamentación y orden del jardín. Sin embargo, los ojos que miran cada movimiento están abiertos, atentos a cualquier irregularidad.

Esa misma vigilancia invisible del jardín está presente en la ciudad cuando Urrutia Lacroix la mira una madrugada al regresar de su última clase. «Llegué a las dos de la mañana, después de atravesar las calles vacías de Santiago, la geometría del toque de queda» (113). Este vaciamiento, esta geometría detenida, es el jardín milimétricamente controlado. Un jardín de artificio. Un jardín sin vida.

Si seguimos la idea de Allen Weiss (1995), quien parte de Foucault, acerca de que «el jardín es usualmente considerado como un microcosmos» (48), la manera en que Bolaño representa el jardín de Pinochet debe leerse como una metáfora del país que el dictador ordena. Más aún, sobre la relación entre jardín y paisaje, Jens Andermann (2014) indica que existe «una tensión (que el jardín debe incorporar como su principio formal y como definición de su propio borde con el entorno) entre las formas de la naturaleza y el orden que les debe imponer el jardinero» (202). Esta tensión se puede trasladar también a la que vive una sociedad enfrentada al orden que un dictador desea aplicar a la fuerza. Mientras la naturaleza tiene sus ritmos, sus tiempos, el jardín la reorienta y la somete a un patrón externo: a un único tiempo posible. Esto podemos notarlo hasta cierto punto Bolańo describe en su novela el estado del campo antes de la dictadura como una «naturaleza salvaje».

\section{El campo sin flores del jardín y Neruda entre «rosas»}

En una escena de la novela se contraponen campo y jardín cuando el sacerdote va de visita al fundo del crítico Farewell. Durante su estancia, Urrutia Lacroix recorre el campo y reflexiona tanto sobre la naturaleza del lugar como sobre sus habitantes. "Todos eran feos. Las campesinas eran feas y sus palabras incoherentes» (32). El cura destaca que los campesinos caminaban «no en línea recta (...) sino en zigzag. (...) Los campesinos que se alejaban eran feos y su singladura en zigzag incoherente» (32-33). Asimismo, Urrutia Lacroix dice: «crucé un canal por el que se arrastraba un agua fangosa. Vi ortigas y toda clase de malas hierbas» (30). Mientras que, recordemos, el jardín de Pinochet tenía un buen aroma, estaba adornado con flores, y en vez de un agua fangosa, "una luna redonda rielaba sobre la superficie regular de una piscina» (110). En definitiva, el cura mira el campo como un espacio feo, desordenado, donde no hay disciplina (un tiempo único), sino distintas formas de vida. Si bien Bolaño describe el atraso de la vida rural de los ańos cincuenta en Chile, su rechazo hacia las formas no ordenadas, no uniformadas, parece contraponerse al modo en como describe el jardín de Pinochet. Por otro lado, el paisaje rural se contrapone aún más cuando Urrutia Lacroix regresa a la casa de Farewell, y se dirige hacia el jardín en el cual un grupo de intelectuales comparte una velada:

En el jardín de Là-bas, junto a una pérgola de madera noble, los invitados de Farewell escuchaban recitar a Neruda. En silencio, me puse junto a su joven discípulo, que fumaba con aire displicente y reconcentrado mientras las palabras del perínclito raspaban las variadas cortezas de la tierra o se elevaban hasta los travesaños tallados de la pérgola y más allá, hasta las nubes baudelairianas que recorrían de una en una los despejados cielos de la patria (34).

Este jardín, cual torre de marfil, se vuelve centro de reunión de la intelectualidad, una que parece no ver el contexto de atraso que la rodea o, sí se quiere, decide no verlo para concentrarse solo en el placer de escuchar la voz del poeta. Este jardín no está sumamente controlado, como en el de Pinochet, sino más bien su distanciamiento hacia la realidad da cuenta de la complicidad intelectual que no se compromete con su realidad sino sólo con la ficción que ella misma construye.

\section{El jardín de pajarillos heridos}

Además de la «intelectualidad cómplice», enfocada en sí misma, Bolaño describe en su novela a otros intelectuales con una participación activa en la dictadura. Cuando una de las tertulias literarias en casa de María Canales, trasunto de la escritora chilena 
Mariana Callejas ${ }^{25}$, termina, y los invitados se marchan, el sacerdote escucha «el canto de los pajarillos en el jardín» (128). Sin embargo, ¿cómo son los cantos de los pajarillos? ¿Qué emiten? Sonidos agudos, que quizá también sean chillidos. Son, tal vez, los mismos sonidos que se ocultan en el sótano de la casa. Los sonidos de la tortura. En otra escena de la novela se revela que mientras se realizaban fiestas con escritores en la casa, en el sótano de la misma torturaban a disidentes políticos ${ }^{26}$. Como en el jardín-país el espacio se ornamenta, los sonidos de la tortura también se ocultan bajo las apariencias de lo uniforme; de lo que sí se supone que existe clandestinamente en un jardín. Por ello, se escuchan como cantos de pájaros, como un sonido aceptado en este jardín-país en el que todo se camufla bajo un forzado artificio. Este sentido del ocultamiento lo destaca Patricia Espinosa (2001) en su reseña sobre Nocturno de Chile al señalar que se trata de «un libro en torno al terror, a la posible verdad, a la moral posible. Un intento de mirar tras la cara visible del mismo poder que hoy intenta seguir convenciendo con su discursividad del ocultamiento» (2001, cursivas mías).

En el caso de Urrutia Lacroix, su ocultamiento se da gracias a su vestimenta de clérigo, al pseudónimo que usa en su escritura crítica y al intentar mantener en secreto su labor como "maestro" de Pinochet. Su capacidad de ocultarse, incluso de disimular, le permite moverse entre distintas esferas. Desde el comienzo de la novela vemos cómo este personaje pasa de ser un desconocido a formar parte de los círculos letrados de su país. Comparte mesa tanto con poetas como Neruda, o críticos como Farewell, así como es admirado por los campesinos que conoce en el fundo de este último. El sacerdote asiste a reuniones del mundo literario local, empieza

25. Mariana Callejas fue una escritora chilena casada con el ex agente de la CIA y sicario Michael Townley. Ambos participaron, como agentes encubiertos de la DINA (Dirección de Inteligencia Nacional), en el asesinato de opositores políticos al régimen de Pinochet, tales como Carlos Prats y Orlando Letelier.

26. «Supe, por otro amigo, que quien se había perdido era un autor de teatro o tal vez un actor, y que había recorrido los infinitos pasillos de la casa de María Canales y de Jimmy Thompson hasta la saciedad, hasta llegar a aquella puerta al final del corredor débilmente iluminado, y había abierto la puerta y se había dado de bruces con aquel cuerpo atado sobre una cama metálica, abandonado en aquel sótano, pero vivo, y el dramaturgo o el actor había cerrado la puerta sigilosamente» (140). a publicar sus poemas y artículos, e incluso realiza un viaje a Europa para continuar con su formación «intelectual». Es decir, en esta figura se intenta formular la versión más canónica del ascenso de un individuo en la "ciudad letrada»". Sin embargo, ¿qué aprende en su viaje de formación por Europa? ¿Qué conocimiento «novedoso" trae de vuelta a su tierra? Aquello que trae en su regreso a su "patria» es cómo mantener incólumes, «sanos» y limpios, los grandes monumentos eclesiásticos de aquello que aparentemente más los daña: los excrementos de palomas. En 58 indicios sobre el cuerpo, Jean-Luc Nancy (2015) señala que «la exterioridad y la alteridad del cuerpo llegan hasta lo insoportable: la deyección, el desperdicio, el innoble desecho que todavía forma parte de él, que todavía es de su sustancia y sobre todo de su actividad» (28). Así, podemos pensar los excrementos (el desecho) como una extensión del cuerpo, o, como dice Nancy, «el exceso de su propia vida» (28). Así también, el pensador francés señala en otro de sus libros, El intruso, que «la verdad del sujeto es su exterioridad y su excesividad: su exposición infinita» (Nancy, 2006: 43). Esta "exposición infinita», este exceso, puede pensarse como aquello que va más allá de la norma, del "gusto exquisito", aquello que deja de ser uniforme; por ejemplo, esas otras actividades corporales que no queremos ver, que se ocultan, pero que están, que existen. Esos residuos, o desechos, son lo que un régimen autoritario no permite, lo que no desea que ocurra, los que intenta limpiar u ocultar en su jardín. Como afirma John Scanlan (2005), «estamos ciegos a la realidad de los desechos porque la sociedad moderna ha creado medios casi perfectos para no recordar» (16). Estos medios son, esencialmente, tecnologías de limpieza, formas de blanqueamiento. Así, pienso que el cura-jardinero aprende en Europa los mecanismos necesarios para mantener el «esplendor» de la monumentalidad del jardín. Lo que exporta del viejo mundo a Chile no es más que el aparato de limpieza del nazismo y de regímenes fascistas, aquello que Bauman denomina

27. Desde la Colonia hasta el presente, la apropiación de la «letra» o del "conocimiento» ha funcionado como mito para el ascenso social y para «la incorporación a los centros de poder» (Rama, 103). Dominar un conocimiento es apropiarse o construir un espacio de poder. En este sentido, Urrutia Lacroix realiza distintos pasos para transitar de ser un joven sacerdote con ínfulas de poeta a convertirse en asesor intelectual del régimen militar. 
como "las técnicas de limpieza» ${ }^{28}$. Estas técnicas de limpieza, para Urrutia Lacroix, tienen como finalidad purificar los edificios eclesiásticos de la suciedad de las palomas. Para ello, el cura encuentra cómo en Europa utilizan halcones que cazan palomas, o las espantan. Ello pareciera ser una metáfora de los militares, del rol que cumple el aparato bélico para la imposición de una forma de pensamiento (o gobierno). Además, también los «halcones» representan a la intelectualidad cómplice, a aquella que disfruta una fiesta escuchando supuestos cantos de pajarillos que no se pueden ver o, si se quiere, que ya cazado esos pájaros y oyen su agonía ${ }^{29}$.

\section{El árbol de Judas y Pinochet como intelectual de «jardines»}

Casi al final de la novela, Urrutia Lacroix, mientras camina por un jardín, recuerda un sueño que tuvo en el que vislumbraba «en el centro del patio (...) un árbol, de especie indiscernible, sin hojas» (135), para más adelante catalogarlo como «el árbol de Judas» (137). El personaje reflexiona sobre su sueño y dice: "tuve un atisbo de comprensión: Chile entero se había convertido en el árbol de Judas, un árbol sin hojas, aparentemente muerto, pero bien enraizado todavía en la tierra negra, nuestra fértil tierra negra en donde los gusanos miden cuarenta centímetros» (138). Así, el árbol de Judas es lo que el jardín, en su búsqueda de artificio, esconde. No es la excepción,

28. Bauman se refiere a la función de la burocracia durante el Holocausto. «Para ese momento, la burocracia había organizado maravillosas técnicas de limpieza que no se podían desaprovechar y dejar que se oxidaran» (137).

29. Asimismo, no se puede dejar de señalar, como lo ha dicho Walter Benjamin, cómo cultura (creación) y barbarie (destrucción) están unidas. Si bien el filósofo alemán lo menciona desde una mirada más universal, al ser el jardín un microcosmos podemos afirmar que ese espacio estético es también un logro dado o posible a través de la destrucción. De ahí que podamos comprender el jardín también como un ensayo, como una puesta en práctica de una forma de ejercer el poder que se desea amplificar. De la misma forma, Mukerji destaca esta relación creación-destrucción en el paisajismo francés. "The political culture of land control that was transforming the French landscape into a marker of the state's power was showcased arounsd the royal residences, particularly Versailles, in the formal gardens that mobilized the same technologies of material power used throughout the state but that employed them to create dramatic visual effects from natural forces» (652). sino la norma lo que realmente rige el jardín-país, pero que se cubre bajo la forma de excepción (el jardín como excepción del orden «natural»). El árbol no tiene ni hojas ni flores. Este árbol de Judas nos hace pensar en el relato "El traje nuevo del emperador» (1837), de Hans Christian Andersen, en el cual unos pícaros engañan a un soberbio rey al darle un traje "que solo las personas no estúpidas podrían ver». Por supuesto, no existe tal ropaje, y solo hacia el final del relato un niño, en su inocencia, se atreve a proclamar que el rey «está desnudo». Si recordamos la caricatura de Pinochet, vestido floridamente como Luis XIV, podemos afirmar que el árbol de Judas no es solo Chile, sino también el dictador, aquel que se camufla bajo un manto de artificio, mientras que en la tierra negra los "gusanos» hacen de las suyas.

Pinochet se "camufla» al describirse a sí mismo más como un sujeto letrado que como un militar o político corriente. A la vez así lo miran otros personajes, como en el caso de Farewell y el cura que lo perciben como un "verdadero" faro. "Algo tiene que tener el caballero que lo haga excepcional», expresa Farewell (114). En esta frase, el crítico no solo condensa su admiración por el dictador, sino también pareciera reconocer que ya los intelectuales no tienen la misma transcendencia que antes. En este sentido, compartimos la reflexión de Tomás Maldonado acerca de cómo los hombres eruditos, los intelectuales de biblioteca, conciben su fragilidad al ser potencialmente sustituidos por nuevas figuras «más eficaces en el ámbito público" (1998: 20). Pinochet se compara con los expresidentes de su país e indica que ninguno de ellos era intelectual. El dictador se siente orgulloso porque se considera superior al haber escrito tres libros ${ }^{30}$ y presume de interesarse por la lectura: ${ }^{31}$ "Yo leo libros de historia, leo libros de teoría política, leo incluso novelas» $(117-118)^{32}$. Sin embargo, son

30. Augusto Pinochet escribió varios libros de tema militar, entre ellos Geopolitica (primera edición: 1968, segunda edición: 1974).

31. En La vida literaria de Augusto Pinochet, Juan Cristóbal Peña da cuenta de la biblioteca del dictador, la cual estaba compuesta por más de 55.000 libros, valorada en tres millones de dólares.

32. En un artículo de prensa se cita una declaración de Pinochet quien señaló: "Yo sé que el marxismo-leninismo es una teoría diabólica. Lo sé por mis estudios: leo 15 minutos diarios» (Ortuzar, 2003). Por su parte, Andrea Jeftanovic (2000), en un texto titulado «El Rol de la Cultura en Chile de la Transición: "Chile = Pinochet", y otras sinopsis de los años 90» cuenta que un periodista le preguntó a Pinochet 
tres libros que pudieran conectarse con el campo militar. Uno de ellos, dedicado a la geopolítica, que vendría a representar esa interpretación e intervención que hace el dictador-jardinero sobre su territorio. Lo ordena, determina qué puede estar y qué debe excluirse. Lo transforma en un jardín de senderos que no se bifurcan. En su libro Geopolítica, Augusto Pinochet (1974) afirma que «el repudio inicial aflorado hacia esta disciplina [la geopolítica] durante la II Guerra Mundial (...) hoy se ha transformado en un sentimiento de simpatía hacia esta novel ciencia» (19, cursivas mías). El autor enfatiza que esa ciencia fue muy combatida "por todos aquellos que veían en ella un estrecho enlace con las ideas totalitarias» (19). Asimismo, indica que si bien la geopolítica no tiene muy limitado su campo de acción, «ella mantiene enlaces con toda ciencia que diga relación con el territorio» (31). Por ello, ninguna hoja puede moverse fuera de su lugar. Por ello, las luces prenden con la presencia del dictador en el jardín. El jardín es, pues, un microcosmos de la geopolítica.

\section{El jardín sin jardinero}

Para cerrar, hacia el final de la novela Urrutia Lacroix visita a María Canales, quien ha perdido su prestigio (su lugar, podríamos decir, de «flor privilegiada» en el «jardín-país») tras la caída del régimen militar. Enseguida el sacerdote observa que

la casa ya no parecía la misma: todo su esplendor, un esplendor nocturno e impune, había desaparecido. Ahora sólo era una casa demasiado grande, con un jardín descuidado en donde la maleza crecía sin control, vertiginosamente, trepando por las rejas como si quisiera velar al paseante ocasional la visión del interior de aquella casa marcada (143).

Me quedo con la imagen de este jardín que, a diferencia del descrito al principio de la novela, no es ni reducido ni modelado/moldeado/manipulado. Se trata de un jardín que desborda los límites de su condición de cerco para adentrarse en otros espacios de los cuales antes era excluido, así como para extenderse y romper con la simetría o un orden exteriormente

acerca de su rutina a lo cual el dictador respondió: «Todas las noches estudio libros de historia, de filosofía, de ciencias políticas, de religión, de economía. Leo por 5 minutos y apago la luz». impuesto. Es un jardín que ya no encuentra resistencias, pero que a la vez no pierde su condición de jardín. Para Chiara Bolognese, el jardín final de la casa de María Canales vendría a ser uno de esos «lugares infernales» que Bolaño suele presentar en su narrativa, "aquellos en donde el infierno se produjo» (100). Ahora bien, el jardín sin orden de Canales no es solo el espacio después del infierno, sino también el lugar que materialmente da cuenta del fin de un régimen dictatorial, se convierte en un espacio que refleja un proceso de transición pues da la posibilidad de que esa «naturaleza controlada» se libere.

Esa casa, y su jardín, es clave para pensarla como espacio político representativo de la dictadura chilena, puesto que no solo Bolaño la representó como lugar donde se vinculan cultura y violencia, sino también otros escritores, ${ }^{33}$ como el caso de Pedro Lemebel en su crónica oportunamente titulada «Las orquídeas negras de Mariana Callejas (o «el Centro Cultural de la Dina»)». En el texto, Lemebel describe la casa de Callejas enfatizando la relación que se establece entre los intelectuales y la violencia, así como destacando el jardín como ese doble lugar de creación y destrucción:

...la casa enclavada en el cerro verde y el paisaje precordillerano y esos pájaros rompiendo el silencio necrófilo del barrio alto. Esa tranquilidad de cripta que necesita un escritor, con jardín de madreselvas y jazmines "para sombrear el laboratorio de Michael, mi marido químico, que trabaja hasta tarde en un gas para eliminar ratas», decía Mariana con el lápiz en la boca. Entonces todos alzaban las copas de Old Fashion para brindar por la alquimia exterminadora de Townley, esa swástica laboral que evaporaba sus hedores, marchitando las rosas que morían cerca de la ventana del jardín (1998: 7).

Lemebel describe el jardín de Callejas como un decorado, una forma de ocultar el horror que se esconde: el del marido "químico" que elabora un "gas» para «eliminar ratas». De ahí que todo esté travestido, quienes observan el jardín ven solo disfraces, y quienes hacen parte de la casa, también se disfrazan bajo la apariencia de personajes socialmente aceptados.

33. Además de Roberto Bolaño y Pedro Lemebel, tenemos la obra El Taller, de Nona Fernández, el cuento "Caída en desgracia», de Carlos Iturra, entre otros. Asimismo, algunos escritores actuales, como Carlos Franz y Gonzalo Contreras, se formaron en su taller y en distintas entrevistas han reflexionado sobre su paso por esa casa. 
Como en la caricatura de Pinochet, en esta crónica de Lemebel los personajes también se retratan, y se miran entre sí, a partir de cómo pretenden mostrar a la sociedad:

Todo el mundo veía y prefería no mirar, no saber, no escuchar esos horrores que se filtraban por la prensa extranjera. Esos cuarteles tapizados de enchufes y ganchos sanguinolentos, esas fosas de cuerpos retorcidos. Era demasiado terrible para creerlo. En este país tan culto, de escritores y poetas, no ocurren esas cosas, pura literatura tremendista, pura propaganda marxista para desprestigiar al gobierno, decía Mariana subiendo el volumen de la música para acallar los gemidos estrangulados que se filtraban desde el jardín (1998: 7).

El discurso de los intelectuales y escritores funciona entonces como forma de decorar el jardín-país para así esconder sus contradicciones, sus problemas y la violencia que allí tiene lugar. Los artistas y los intelectuales no pueden ver el horror que sucede porque este se encuentra disfrazado, de la misma manera que en la caricatura de la revista APSI donde Pinochet aparece vestido a la usanza de la aristocracia francesa de otro siglo. El horror se intenta ocultar con el apoyo de la creación artística.

Por otro lado, ese no control presente en el jardín «abandonado» de la casa de María Canales tras el derrocamiento de la dictadura es la mayor expresión de libertad que encuentro en esta novela. El dejar fluir la naturaleza intacta (sin intervención externa), esa pura virtualidad, no debe leerse como un descontrol, sino como otro orden, como una respuesta a la pregunta ¿y qué viene después del horror? Todo jardín intenta apropiarse de la mirada. Este otro jardín, el último representado en Nocturno de Chile, busca simultáneamente ocultar y exhibir un espacio de la dictadura. Lo oculta porque no deja ver su interior, como se señala en la novela, pero al mismo tiempo lo exhibe porque la maleza llama la atención sobre aquella que está cerrando. En ese sentido, la virtualidad del jardín solo se actualiza en la mirada. Este último jardín es un fantasma, un espectro que da cuenta de conflictos no resueltos alrededor de la casa:

Entramos a la casa. Ya no había tantos muebles como antes y la decrepitud del jardín tenía su correlato en las habitaciones, que yo recordaba luminosas, y que ahora aparecían como bañadas por un polvillo rojizo, suspendidas en un tiempo diacrónico en donde se sucedían escenas incompresibles, tristes, lejanas (143-144).
La mirada del cura no consigue develar ni dar respuesta a lo ocurrido, más allá de describir una escena de deterioro. Su capacidad de «ver» y «ordenar» la realidad que desarrolla tanto en sus tertulias literarias y políticas, como en su viaje a Europa, no le sirven ahora que el contexto ha cambiado. El descuido del jardín, y de la casa, responden a un cambio de régimen, una nueva manera de mirar y de ordenar el espacio. Formado en las reuniones literarias que ignoraban su alrededor e instruido en que a través del uso de "halcones» se podía "borrar» a quienes «ensucian» la sublimidad de los «monumentos», el personaje del cura no puede pensar en «otras formas» de leer/mirar a la sociedad. Esa intelectualidad ya no funciona en el nuevo jardín porque es incapaz de ver vida donde ellos miran malezas. Más aún, esa intelectualidad, cómplice de la dictadura, no reconoce el horror aunque lo tenga de frente. En la novela, el personaje del cura seńala "yo nada vi, nada supe hasta que fue demasiado tarde» (142), en referencia a los actos de tortura que ocurrían al interior de la casa de Canales. Urrutia no puede ver porque su mirada ha sido apropiada por el jardín del dictador: la belleza del orden lo enceguece y le imposibilita percibir la destrucción que detrás se esconde.

En conclusión, Roberto Bolaño fabula en Nocturno de Chile distintas modalidades de la imagen y de la metáfora del jardín como un modo de dar cuenta de la historia política de Chile, especialmente del contraste entre la dictadura, reflejada en el jardín de Pinochet, y la posterior transición, reflejada en el jardín de María Canales. En este «jardín-país» que hemos denominado, Bolaño hace de la cultura material un reflejo de la situación política. El dictador puede pensarse como un jardinero que ordena el país con ese "gusto exquisito" como señala Urrutia Lacroix, uno que hace del territorio un espacio controlado por su deseo.

\section{Bibliografía}

Andermann, Jens. "Cosmopolitismos telúricos: jardín y modernidad en Latinoamérica». Revista de Crítica Literaria Latinoamericana, 79 (2014): 201-215.

Araya, Francisca. Historia de la Revista Apsi. Santiago: LOM, 2007.

Bauman, Zygmunt. Modernidad y Holocausto. Madrid: Sequitur, 1998.

Bauman, Zygmunt. Legislators and Interpreters. On modernity, post-modernity and intellectuals. Oxford: Polity Press, 1989. 
Bolaño, Roberto. Nocturno de Chile. Barcelona: Anagrama, 2014.

Bolognese, Chiara. Pistas de un naufragio. Cartografia de Roberto Bolaño. Santiago: Margen, 2009.

Corominas, Joan. Diccionario crítico etimológico castellano e hispánico. Madrid: Gredos, 1984.

Espinosa, Patricia. "Vericuetos de una conciencia peligrosa». 2001. http://www.letras.s5.com/ bolano1804027.htm Consultado el 3 septiembre 2016.

FARIELlo, Francesco. La arquitectura de los jardines. De la antigüedad al siglo XX. Barcelona: Reverte, 2004.

Foucault, Michel. Espacios otros. 1999. $<$ http://148.206.107.15/biblioteca_digital/estadistica.php?id_host=6\&tipo=ARTICULO\&id $=1932 \&$ archivo $=7-132-1932$ qmd.pdf\&titulo $=$ Espacios $\% 20$ otros> Consultado el 3 agosto 2016.

GonzÁlez, Daniuska. La escritura bárbara. La narrativa de Roberto Bolaño. Lima: Fondo Editorial Cultura Peruana, 2010.

Jeftanovic, Andrea. «El rol de la cultura en Chile de la transición: 'Chile = Pinochet', y otras sinopsis de los años 90». En: http://www.letras.s5.com/aj300608. html (2000).

Lemebel, Pedro. De perlas y cicatrices. Santiago: LOM, 1998.

López-VICUÑA, Ignacio. «Malestar en la literatura: escritura y barbarie en Estrella Distante y Nocturno de Chile de Roberto Bolaño». Revista Chilena de Literatura, 75 , (2009): 199-215.

Maldonado, Tomás. ¿Qué es un intelectual? Aventuras y desventuras de un rol. Barcelona: Paidós, 1998.

MukerjI, Chandra. «The Political Mobilization of Nature in Seventeenth-Century French Formal Gardens». Theory and Society, 23.5 (1994), 651-677.

NANCY, Jean-Luc. 58 indicios sobre el cuerpo. Extensión del alma. Buenos Aires: La Cebra, 2015.

Nancy, Jean-Luc. El intruso. Buenos Aires: Amorrortu, 2006.

Ortuzar, Ximena. «Allende, el presidente que nunca se rindió, vociferaba: "nada de diálogo; ofrézcanle un avión y en el camino ese avión se cae"». $L a$ Jornada (11 sep. 2003). <http://www.jornada.unam. $\mathrm{mx} / 2003 / 09 / 11 / 052 \mathrm{n} 1$ con.php?printver $=1 \& \mathrm{fly}=>$ Consultado el 1 Sep 2016.

Pinochet, Augusto. Geopolitica. Santiago: Andrés Bello, 1974

Rama, Ángel. La ciudad letrada. Santiago: Tajamar, 2004.

Ricoevr, Paul. «Ética y Moral». Gómez, Carlos (ed.). Doce textos fundamentales de la ética del siglo XX. Madrid: Alianza, 1990: 241-255.

SCANLAN, John. «La basura importa». 2005. <http:// es.scribd.com/doc/190125931/Scanlan-La-BasuraImporta\#scribd> Consultado el 10 septiembre 2016.

WeIss, Allen. Mirrors of Infinity. The French Formal Garden and 17th-Century Metaphysics. New York: Princeton Architectural Press, 1995. 